УДК 35.07:330.123.6

DOI 10.33514/BK-1694-7711-2019-1-152-157

Ибрагимова А.С.

Кыргыз Республикасынын Президентине караштуу Мамлекеттик башкаруу академиясынын магистранты, Кыргызстан

Ибрагимова А.С.

Магистрант Академии Государственного управления при Президенте Кыргызской Республики, Кыргызстан

Ibragimova A. S.

Undergraduate Academy of Public Administration under the President of the Kyrgyz Republic, Kyrgyzstan

\author{
КЫРГЫЗ РЕСПУБЛИКАСЫНДАГЫ СОЦИАЛДЫК КОЙГОЙЛОРДУ ЧЕЧУУГӨ \\ БАГЫТТАЛГАН БЕЙӨКМӨТ УЮМДАРДЫН ИШМЕРДУУЛУГУНДӨГУ \\ МААЛЫМАТТЫК - БАЙЛАНЫШТЫК ТЕХНОЛОГИЯЛАРДЫН ОРДУ \\ РОЛЬ ИНФОРМАЦИОННО - КОММУНИКАЦИОННЫХ ТЕХНОЛОГИЙ \\ В ФУНКЦИОНИРОВАНИИ НЕПРАВИТЕЛЬТВЕННЫХ ОРГАНИЗАЦИЙ \\ В РЕШЕНИИ СОЦИАЛЬНЫХ ПРОБЛЕМ КЫРГЫЗСКОЙ РЕСПУБЛИКИ
}

\title{
THE ROLE OF INFORMATION AND COMMUNICATION TECHNOLOGIES IN THE FUNCTIONING OF NON-GOVERNMENTAL ORGANIZATIONS IN THE SOLUTION OF SOCIAL PROBLEMS OF THE KYRGYZ REPUBLIC
}

Аннотация: Акыркы он жылдыкта, айрым өлкөлөрдүн эл аралык мамилелер, ички жана тышкы көйгөйлөргө байланыштуу маселелерин чечүүдө, өкмөттүк эмес уюмдар көз карандысыз катышуучунун ролун ойношот. Бардык коомдук - саясий жана эл аралык укуктук маселелер жана көйгөйлөр, көп учурда бейөкмөт уюмдардын жарым - жартылай таасири астында чечилип келет. Кээ бир эл аралык уюмдар айрым мамлекеттерге караганда, көптөгөн өлкөлөрдө чоң таасирге ээ. Ошондуктан, бул уюмдардын ишмердигине көбүрөөк көңүл буруу жана көмөк көрсөтү талап кылынат.

Аннотация: В последние десятилетия неправительственные организации активно выступают в роли независимого участника при решении проблем внутренних и внешних отдельных стран и международных отношений в целом. Все общественно - политические и международно - правовые вопросы и проблемы решаются, в частности, под их частичным воздействием. Многие международные неправительственные организации имеют огромные влияния во многих странах, чем отдельные государства. Поэтому такие организации требуют большего внимания и содействии в их деятельности.

Abstract: In recent decades, non-governmental organizations have actively acted as an independent participant in solving problems of internal and external individual countries and international relations in general. All sociopolitical and international legal issues and problems are solved, in particular, under their partial influence. Many international NGOs have enormous 
influence in many countries than individual states. Therefore, such organizations require more attention and assistance in their activities.

Негизги сөздөр: үчүнчү сектор; социалдык көйгөйлөр; бейөкмөт уюм; кирешесиз уюм; маалыматтык - байланыш технологиялары; маалыматтык коом; маалыматтык технологиялар; социалдык тармак; интернет булактары.

Ключевые слова: третий сектор; социальные проблемы; неправительственная организация; некоммерческая организация; информационно - коммуникационные технологии; информационное общество; информационные технологии; социальные сети; интернет ресурсы.

Keywords: third sector; social problems; non - governmental organization; non-profit organization; information and communication technologies; information society; information technology; social networks; Internet resources.

В последние годы в мире растет интерес к сфере деятельности, которая выходит за рамки государственной или коммерческой. Эта сфера составляет основу нового исторического формирования - гражданского общества.

Основу гражданского общества составляет некоммерческий сектор, иные его названия: бесприбыльный, добровольческий, независимый или же третий. Третий сектор это благотворительность, социальные услуги, защита прав, экология и очень многое другое, без чего современное общество не функционирует. Государство решает те социальные проблемы, на решение которых у него хватает ресурсов. Бизнес решает проблемы, за решение которых можно получить доход. Третий сектор занимается решением тех проблем, на которых нет ресурсов ни у государства, ни у бизнеса.[1]

В нашей стране третьим сектором принято считать некоммерческие организации, созданные в соответствии со ст. 10 Закона Кыргызской Республики «О некоммерческих организациях» от 15 октября 1999 года N 111. В Кыргызстане под некоммерческими организациями в основном понимают неправительственные организации. Следует провести четкую грань между Неправительственными организациями (далее - НПО) и Некоммерческими организациями (далее - НКО).

НПО - это организации, созданные без участия государства, основной сферой деятельности которых является общественно полезная, социальная деятельность. Существуют другие аналогичные формулировки НПО, среди которых многие придерживаются следующей: "В число НПО включаются лишь светские некоммерческие организации, не преследующие политических или преимущественно экономических целей".[2]

Объяснения к тому, какие организации считать НКО, отличаются от одной организации к другой. Даже Устав Организации объединенных наций не дает четкого определения, а лишь указывает на них для своих целей. Это означает отсутствие универсального понятия НКО. Согласно резолюции ООН, под НКО понимается организация, которая не учреждена каким - либо государственным органом или на основе межправительственного соглашения и удовлетворяет следующим условиям:

- имеет "представительную структуру";

- располагает "соответствующими механизмами отчетности перед своими членами";

- ее члены "осуществляют эффективный контроль над ее политикой и деятельностью путем использования права голоса и через другие соответствующие демократические процессы принятия решений".[3] 
НКО как говорит само название организации - некоммерческая, не имеет каких либо коммерческих целей в своей деятельности. У НПО те же цели, но при этом могут осуществлять коммерческую деятельность.

Количественный рост неправительственного сектора привел к тому, что сейчас существует около 16 тыс. неправительственных организаций. Анализ развития неправительственных организаций Кыргызской Республики показывает, что в настоящее время сложились довольно устойчивые группы неправительственных организаций по нижеследующим направлениям:

- экологическое,

- детское и молодежное,

- женское,

- медицинское,

- в области культуры, искусства, науки, образования,

- по поддержке общественных инициатив,

- многопрофильное,

- общества инвалидов,

- по реабилитации детей - инвалидов и т.д.

В деятельности неправительственных и некоммерческих организации использование передовых технологии - это эффективный метод решения социальных проблем. Неслучайно многие страны мира перешли на так называемое «информационное общество», некоторые - в процессе перехода, в зависимости от различных факторов, влияющих на процесс.

Информационное общество - это высокоразвитое общество, использующее информационные технологии, с улучшенными инфраструктурами, которые способствуют производству информационных ресурсов и обеспечивают доступ к информации.[4]

Современные технологии обладают гибкостью и приспосабливаемостью к воздействиям и изменениям внешней среды. В ходе модернизации социальной среды, информационные технологии представляют собой основной фундамент общества, так как с их помощью можно улучшить и автоматизировать процессы обработки данных информации, которые в последние годы являются особенно значимым жизненном процессе человеческого общества.[5]

Стоит отметить, что информационные технологии, прочно закрепившись в нашей жизни, облегчили многие процессы. До использования компьютерных технологий занимало большое количество времени документооборот и хранение информации. На сегодняшний день сбор, разработка, хранение, обработка, реализация информации и знаний осуществляется передовыми технологиями. При этом результаты точные, и есть гарантия конфиденциальности.

В современном информационном обществе главным ресурсом является информация. Процессы с ней базируются на информационных и коммуникационных технологиях. Информационные и коммуникационные технологии - это методы, устройств и производственных процессов, используемых обществом для сбора, хранения, обработки и распространения информации. Применения новых информационно - коммуникационных технологических решений, использование которых позволяет повышать эффективность функционирования организации. 
Передовые технологии в социальной сфере, а именно в решении социальных проблем, дают возможность масштабировать всю деятельность. Информационные технологии в социальной среде на сегодняшний день предоставляют:

- сбор, накопление событий и статистической информации об общественных связях и развитии, социальном составе населения, возможности социальной инфраструктуры, результативности предоставляемых мер общественной охраны, классах и слоях населения, нуждающихся в особом внимании;

- сохранение данных в таком виде, который предоставлял бы легкое и быстрое нахождение, своевременное обновление и предъявление данных по мере надобности;

- сопоставление показателей действительных социальных процессов с показательными образцами общественного воспроизведения населения, учитывая скорость их преобразований;

- взаимодействие общегосударственных, общеотраслевых и областных составов исследований развития деятельности социальной среды; эффективное, своевременное и полное предоставление данных и информации в положенном виде управляющим различных уровней.[6]

Информационные технологии, играя роль элемента и функции информационного общества, стабилизируют и усовершенствуют системы регулирования новых сетей. Они распределяют большое количество информации на всемирном, областном и местном уровнях, а также имеют огромное значение в формировании техники и её структуры, в увеличении значения прогресса и динамично охватывают огромные области социальной сферы.

Информационные технологии охватывают все ресурсы, необходимые для управления информацией. Это доказывает тот факт, что с помощью ИКТ созданы программы, сайты, телефоны горячей линии для поддержания постоянной связи с обществом.

Телефоны горячей линии - наиболее распространенный и удобный метод поддержания связи с обществом. Ранее такие службы предоставляли только государственные учреждения. Сегодня же люди могут звонить напрямую в кризисные центры помощи неправительственных организаций, получают бесплатные консультации. Организации в свою очередь получают возможность предоставления помощи населению охватывая все регионы страны и большее количество населения. В случае необходимости выезжают по месту требования и реагируют своевременно.

Интернет ресурсы дали огромную возможность и расширили круг функциональности передовых технологии. Ведь с помощью ИКТ можно легко найти нужную организацию, ведь каждая из них имеет свой Веб - сайт, где содержится вся информация: функция организации; контактные данные; адреса и т.д. На сайте многих организаций есть возможность получить онлайн консультацию, оставить заявку или же заказать обратный звонок. Даже в таких известных коммерческих сайтах как Lalafo, Diesel есть отдельный раздел объявлений о помощи.

Так же социальные сети вносят свой вклад для информирования граждан. С помощью них решаются проблемы, с которыми не в силах справится одна организация, такие как, например, сбор средств, вещей для уязвимых категорий населения. В таких случаях обращения в социальных сетях, или объявления в известных сайтах помогают за короткое время собрать нужные средства для нуждающихся. В настоящее время такие 
социальные сети как Инстаграм, Фейсбук и др. пользуются особой актуальностью где можно увидеть зарегистрированных общественных организаций.

Все эти процессы оказывают значительное влияние на масштабность социальной помощи, его развития, в деятельность неправительственных организаций. Благодаря ИКТ жизнь людей упрощается, а деятельность таких организаций, которые направлены на помощь социально уязвимым категориям населения становятся эффективнее.

Кыргызская Республика на стадии совершенствования ИКТ и перехода к информационному обществу. На сегодня уже запущены многие проекты в государственных учреждениях и функционируют успешно. Проведены мероприятия для поддержания социальной сферы.

К примеру, создание Веб - портала государственных грантов на финансирование общественно полезных проектов. Веб - портал представляет собой информационно сервисный мультимедийный централизованный Интернет-ресурс, размещенный в сети Интернет по адресу http://vww.gosgrantynasotsproekty.gov.kg.

Интерфейс портала государственных грантов представляет собой сводную таблицу, позволяющую заинтересованным лицам получить на одной строке портала всю необходимую информацию о той или иной социальной программе, согласно которой выделены государственные гранты на финансирование общественно полезных проектов, от момента объявления конкурса до завершения их реализации.[7]

В настоящее время, неравномерность развития неправительственного сектора в регионах, особенно в сельской местности, является значимым минусом. Неправительственные организации активно функционируют в основном, в крупных областных центрах. Следовательно, население в отдаленных регионах страны не достаточно информировано и не могут получить социальную помощь от неправительственных организаций в той или иной форме. Не информированность отдаленных регионов страны обуславливаются тем, что уровень развития ИКТ очень низок, плохое оснащение передовыми технологиями, а в некоторых регионах вовсе отсутствуют.

2019-й год объявлен годом развития регионов и цифровизации страны, в целях дальнейшего развития регионов. Предусмотрены введения новых технологий в повседневную жизнь общества, тем самым создают новые возможности для развития гражданского сектора в отдаленных регионах страны. Это оказало бы позитивное влияние на создание новых рабочих мест, а так же информированию граждан об их правах и свободах.

\section{Список использованной литературы:}

1. Бородкин Ф.М. Третий (неприбыльный] сектор общества /Состояние третьего (неприбыльного) сектора в обществе: Экспертные статьи. - Новосибирск, 1996.

2. Мысин С. В. Сущность и понятие неправительственных организаций. М.. 2012.

3. See: The Conscience of the World: the Influence of Non-Governmental Organizations in the UN System / Ed. by Peter Willets. Washington D.C.: The Brooklyn Institution, 1996. 
4. Григорьева Д. Р., Попченко А. С. Применение информационных технологий в социальной сфере // Молодой ученый. - 2015. - №11. - C. 177-179. — URL https://moluch.ru/archive/91/19119/

5. Григорьева Д. Р., Попченко А. С. Применение информационных технологий в социальной сфере // Молодой ученый. - 2015. — №11. — C. 177-179. — URL https://moluch.ru/archive/91/19119/

6. Интернет-ресурс:http://federalbook.ru/files/SVAYZ/saderzhanie/Tom \%2010/VI/

Chechenov.pdf

7. http://cbd.minjust.gov.kg/

\section{References:}

1. Borodkin F.M. Third (non-profit) sector of society / State the third (non-profit) sector in society: Expert articles. - Novosibirsk, 1996.

2. Mysin S.V. Essence and the concept of non-governmental organizations. M .. 2012.

3. See: The Influence of Non-Governmental Organizations in the UN System / Ed. by Peter Willets. Washington, DC: The Brooklyn Institution, 1996.

4. Grigorieva D. R., Popchenko A. S. Application of information technologies in the social sphere // Young Scientist. - 2015. - №11. - p. 177-179. - URL https://moluch.ru/archive/91/19119/

5. Grigorieva D. R., Popchenko A. S. Application of information technologies in the social sphere // Young Scientist. - 2015. - №11. - p. 177-179. - URL https://moluch.ru/archive/91/19119/

6. Internet resource: http: //federalbook.ru/files/SVAYZ/saderzhanie/Tom\% 2010 / VI / Chechenov.pdf

7. http://cbd.minjust.gov.kg/

Рецензент: к.т.н., проф. Абдрахимова Н. Д. 